\title{
Clinical, endoscopical and morphological efficacy of mesalazine in patients with irritable bowel syndrome
}

This article was published in the following Dove Press journal:

Clinical and Experimental Gastroenterology

15 June 201 I

Number of times this article has been viewed

\section{Andrey E Dorofeyev' \\ Elena A Kiriyan ${ }^{2}$ \\ Inna V Vasilenko' \\ Olga A Rassokhina' \\ Andrey F Elin'}

'National Medical University, Donetsk, Ukraine; ${ }^{2}$ Gastroenterological Center of Poltava Hospital Clinic, Poltava, Ukraine
Correspondence: Andrey E Dorofeyev National Medical University,

Chair of Internal Medicine \#2,

Dzerzhinsky pr.I2/I2, 8300I,

Donetsk, Ukraine

Tel +380 623482847

$\mathrm{Fax}+380623868152$

Email dorofeyev@med.finfort.com
Objectives: The aim of this study was to analyze the clinical efficacy and cytomorphologic changes of colon mucosa following the treatment of patients suffering from irritable bowel syndrome (IBS) with mesalazine (5-aminosalicylic acid [5-ASA]).

Methods: In this controlled, randomized, blind clinical trial, a total of 360 patients with varying subtypes of IBS were randomly treated with $500 \mathrm{mg}$ of mesalazine qid or by standard therapy without mesalazine for a period of 28 days. Pre- and post-treatment pain intensity, pain duration, meteorism, stool abnormalities and endoscopic parameters were monitored, and biopsies or brush biopsies were examined histologically.

Results: Treatment of IBS patients with mesalazine significantly reduced intensity and duration of pain in all subtypes of IBS, except for duration of pain in the subtype "undifferentiated", where the difference was not significant. In addition, in patients with diarrhea type and undifferentiated type of IBS, mesalazine also significantly reduced the abnormal stool pattern. In comparison to the control group, administration of mesalazine reduced the incidence of endoscopic and cytomorphologic changes of the bowel mucosa, including changes in colon mucus, mucus production, cytologic or histologic parameters, epithelial cell degeneration, appearance of leukocytes and macrophages and cell infiltrations.

Conclusion: Mesalazine was effective in reducing several symptoms characteristic of IBS. It significantly reduced pain intensity and duration and improved cytohistologic parameters of the bowel mucosa.

Keywords: 5-amino salicylic acid, 5-ASA, abdominal pain, irritable bowel syndrome, IBS, meteorism, stool abnormalities

\section{Introduction}

Irritable bowel syndrome (IBS) is the most common functional bowel disorder. It is characterized by abdominal pain, bloating and disturbed defecation. The first report on IBS dates to $1818 .^{1}$

Morbidity varies from $30 \%$ to $50 \%$ in Europe, the United States and Japan, and amounts to more than $60 \%$ in post-Soviet countries. ${ }^{2-4}$ In spite of numerous attempts to discover the triggers, etiology and pathogenesis, the pathophysiology of the disease is still unclear. The influence of psychogenic disorders, visceral hypersensitivity and abnormal bowel motility in genesis of IBS is broadly acknowledged. ${ }^{3,5,6}$

Bowel infections, bacterial overgrowth syndrome, antibiotics, stress and unfavorable dietary habits can precede visceral hypersensitivity and lead to a clinical manifestation of IBS. Although there is no specific morphologic correlate of IBS, 
these predictors can affect the colon microbiota and the local immune system, decrease the protective properties of the bowel mucosa, impair mucus production, and may be caused by only minimal alterations on the cellular level.

Histomorphologic analysis of biopsies in IBS is often negative with respect to pathological findings. Occasionally minimal violations or initial signs of edema of the colon mucosa, an increase in diameter of capillaries, constriction or dilatation of crypts, abundance of mucus in crypts, slight increase in number of goblet cells, dystrophy of solitary epithelial cells, increased number of fibroblasts within the stroma and cellular infiltrations are detectable. The detection of minor lesions is often accompanied by a decrease of proliferation and enhanced apoptosis of colonocytes. ${ }^{3,7}$ Progression of the disease leads to more pronounced morphological changes of the colon mucosa epithelium: reduced frequency of serotonin-producing cells and mast cells and increased frequency of secondary cells and increasing number of cellular infiltrations by eosinophils, neutrophils, lymphocytes, plasmocytes and fibroblasts of stroma. ${ }^{7}$ These morphological criteria are signs of inflammatory processes and activation of immune mechanisms, and could explain why IBS often is refractory to standard types of treatment. Elimination of inflammatory processes in colon mucosa could be one of the most promising targets of therapy for IBS patients.

Progress in the development of diagnostic tools, such as positron emission tomography and functional magnetic resonance imaging of the brain, have contributed considerably to understanding of the brain-gut interaction, ${ }^{8,9}$ indicating a possible psychophysiologic component, ${ }^{10,11}$ in addition to the hypothesis that altered motility is the primary underlying pathophysiologic basis of IBS. Most recently, evidence has accumulated suggesting that immune activation affects intestinal function and sensory perception as part of symptom generation in patients with IBS. ${ }^{12,13}$ However, these results are controversial, because contradictory results have been presented by several authors. ${ }^{14,15}$

The first attempt to classify IBS was published by Manning et $\mathrm{al}^{16}$ followed by Kruis et al six years later. ${ }^{17}$ Several consensus conferences subsequently tried to develop diagnostic criteria for the classification and safe diagnosis of gastrointestinal disorders ("Rome criteria"18-20 Table 1, Table 2). The validity of the Rome criteria has been reported in several studies. ${ }^{21,22}$

Due to the uncertainty of the pathophysiologic basis of IBS, numerous studies attempted to find a rationale for
Table I Diagnostic criteria according to the latest issue of "Rome III"2

Recurrent abdominal pain or discomfort* at least 3 days/month in the last 3 months associated with two or more of the following:

I. Improvement with defecation

2. Onset associated with a change in frequency of stool

3. Onset associated with a change in form (appearance) of stool

Criterion fulfilled for the last 3 months with symptom onset at least

6 months prior to diagnosis.

Notes: *Discomfort" means an uncomfortable sensation not described as pain. In pathophysiology research and clinical trials, a pain/discomfort frequency of at least 2 days a week during screening evaluation is recommended for subject eligibility.

the reliable pharmacological treatment of this disease. The failure of corticosteroids stimulated the targeting of the immune system, eg, by mast cell stabilizers. ${ }^{14}$ Moreover, the therapeutic potential of aminosalicylates, well known for their benefits in chronic inflammatory bowel diseases, has attracted renewed interest as a potential cure for IBS. ${ }^{12}$ To better study both relief and outcome in IBS, the Rome foundation initiated a complex systematic review and metaanalysis of the psychometric and performance characteristics of primary endpoints used in large multicenter therapeutic trials for irritable bowel syndrome using pharmacological approaches. $^{23}$

\section{Patients and methods}

\section{Study sites and design}

The study was performed in three centers in the Ukraine between 2006 and 2009, as a controlled post-marketing observational study with 360 patients diagnosed with an irritable bowel syndrome and sub-grouped in accordance with the Rome III criteria.

As a primary outcome parameter, we selected pain intensity. Secondary parameters were pain duration, meteorism, stool abnormalities and histocytologic parameters.

Table 2 Subtyping of IBS by predominant stool pattern modified according to Longstreth ${ }^{2}$

I. IBS with constipation (IBS-C) - hard or lumpy stools $\mathrm{s}^{\mathrm{a}} \geq 25 \%$ and loose (mushy) or watery stools ${ }^{\mathrm{b}}<25 \%$ of bowel movements . $^{\mathrm{c}}$.

2. IBS with diarrhea (IBS-D) - loose (mushy) or watery stools ${ }^{b} \geq 25 \%$ and hard or lumpy stool ${ }^{\mathrm{a}}<25 \%$ of bowel movements ${ }^{\mathrm{c}}$.

3. Mixed IBS (IBS-M) - hard or lumpy stools ${ }^{\mathrm{a}} \geq 25 \%$ and loose (mushy) or watery stools ${ }^{\mathrm{b}} \geq 25 \%$ of bowel movements ${ }^{\mathrm{c}}$.

4. Undifferentiated (IBS-U) - insufficient abnormality of stool consistency to meet criteria for IBS-C, $-D$, or $-M^{c}$.

Notes: ${ }^{B}$ Bristol Stool Form Scale I-2 (separate hard lumps like nuts [difficult to pass] or sausage-shaped but lumpy); 'Bristol Stool Form Scale 6-7 (fluffy pieces with ragged edges, a mushy stool or watery, no solid pieces, entirely liquid); ' In the absence of use of antidiarrheals or laxatives. 


\section{Ethics}

The study was approved by the ethics committees of the National Medical University of Donetsk and the Gastroenterological Center of Poltava Hospital Clinic, Poltava, Ukraine, according to the legal requirements of the State of Ukraine.

\section{Diagnosis of IBS}

Diagnosis of IBS was established according to Rome III criteria (2006) and included: Recurrent abdominal pain or discomfort for $\geq 3$ days per month during the last 3 months, associated with $\geq 2$ of the following:

- Improvement of defecation

- Changes in stool frequency

- Changes in stool consistency

Diagnostic criteria needed to have been fulfilled for the last 3 months with symptom onset $\geq 6$ months prior to diagnosis.

Patients with IBS were divided into subgroups depending on stool pattern according to the Bristol Stool Form Scale.

Occurrences of infections were assessed by anamnesis from the beginning throughout the duration of IBS. Post infectious IBS was considered as a special form of IBS: we did not exclude this group of patients from the study. Absence of any bowel infection was confirmed by microbiological stool examination before diagnosis of IBS and inclusion into the study.

Any organic pathology was excluded first of all (in compliance with Rome III criteria) by exclusion of the specific alarm symptoms such as first symptoms at age $\geq 50$ years, loss of weight, blood in stool, fever, cancer anamnesis in relatives.

Besides histomorphologic analysis of the biopsies we proved absence of any organic pathology or infection. Evidence of inflammation (hyperemia, edema, granulations) were considered as a mild inflammatory process in IBS.

Genetic predisposition to IBS was not found in investigated patients. Different dietary abnormalities associated with specific IBS types (constipation or diarrhea) were found in all patients. However, patients with a strict diet regimen (eg, vegetarians) were excluded from the study.

\section{Statistical analysis}

Statistical analysis started from verification of results of normal dispensation by W-test (Shapiro-Wilk) and Chi-square test. Descriptive statistics with calculation of mean values, standard deviations and median were performed. Significance of differences of mean values was determined by Student's $t$-test.

\section{Patients}

A total of 240 patients from an industrial region with unfavorable ecology and 120 patients from an agricultural region without this negative impact were recruited. The gender distribution was 105 (29.2\%) men and 255 (70.8\%) women. Average age was $43.2 \pm 3.3$ years. Diagnosis of IBS and sub-grouping was based on clinical symptoms according to Rome III criteria, 2006, ${ }^{2}$ as described in Table 2.

Patients were randomized in 2 groups. Each third patient with any type of IBS was assigned to the treatment group and obtained mesalazine (Salofalk ${ }^{\circledR}$ ) $2.0 \mathrm{~g}$ per day for 28 days. Thus 120 IBS patients received $500 \mathrm{mg}$ tablets qid after a meal. The remaining 240 IBS patients were assigned to the control group and received a standard treatment without mesalazine.

Standard treatment according to Rome III was followed during the investigation. Patients with diarrhea received loperamide (2-4 mg when necessary), patients with constipation received psyllium husks (Plantago ovata, Mucofalk $^{\circledR}, 3.25 \mathrm{~g}$ bid with meals) or lactulose syrup (15-20 mL bid); patients with abdominal pain syndrome received mebeverine $400 \mathrm{mg}$ per day. Some patients with severe meteorism received simethicon limited to $3-5$ days.

Before and after treatment, patients characterized their pain intensity by a visual-analog scale $(0=$ no pain to $10=$ worst imaginable pain). Duration of pain, incidence of meteorism and stool abnormalities were queried and documented by the physicians.

Endoscopy was done for all patients before and after treatment. Colonoscopy was done for 200 patients and sigmoidoscopy for 160 patients. During endoscopy the color and intensity of hyperemia, evidence of edema and granulations scattering reflected light in colon mucosa were investigated. Characteristics of vascular pattern, presence of mucus on the colon wall and haustrations were also analyzed.

Before and after 1 month of treatment, endoscopy was carried out on each patient by the same physician.

In addition to visual examination during endoscopy, biopsies of the colon mucosa were taken in 90 patients, but in 150 patients brush-biopsies were preferred.

Brush-biopsies were performed by an abrasive brush brought in contact with visually abnormal or suspicious areas of the colon mucosa. Thereafter the material was transferred to a microscope slide and air dried. The samples were then stained according to the Pappenheim method 
(May-Grünwald-Giemsa solution, ie, methylene blue plus eosin in a methanolic solution for 3 minutes). In brushbiopsies the number and type of epithelial cells, leukocytes, erythrocytes, lymphocytes and bacteria were analyzed.

For histologic analysis, biopsies of the colon mucosa were chemically fixed in a 5\% formaline solution, subjected to a conventional paraffin embedding procedure and subsequent staining of the 2-3 $\mu \mathrm{m}$ sections by hematoxyline-eosin-alcian blue at pH 1.0 and 2.5 for the determination of sulfated and non-sulfated glucosaminoglycans and glycoproteins, and for goblet cells and colon mucus. To characterize the mucus production, the Periodic Acid Schiff reaction (PAS-reaction) was used.

Histological sections were examined with respect to the number and maturity of goblet cells as well as the amount and maturity of the mucus. Furthermore, the intensity of cell infiltrations and their character was determined.

\section{Results}

\section{Patients' age and duration of IBS symptoms}

A total of $291(80.8 \%)$ patients came down with IBS before the age of 45 years. In $7.5 \%$ of all patients IBS was diagnosed between 56 and 65 years of age (no significant difference between males and females). The incidence of IBS was highest in males at the age between 26 to 35 years ( $\mathrm{n}=39,37.1 \%[P<0.01$ as compared with females, $\mathrm{n}=60$, $23.5 \%$ and as compared with the total, $\mathrm{n}=99,27.5 \%])$. The highest incidence of IBS in women was in the age group of 15-25 years. There was no significant difference in the age distribution of women compared with the intention-to-treat population (Figure 1).

At first diagnosis, duration of IBS varied from 6 months to 25 years. Most females had symptoms of IBS for a period of $5-10$ years $(79.4 \%$ of this group, $n=81)$, most males suffered from IBS for a period of $1-3$ years $(35.9 \%$ of this group, $n=42$ ) (Figure 2).

At first diagnosis, patients were allocated to four categories of IBS according to the Rome III criteria: IBS with constipation (IBS-C), IBS with diarrhea (IBS-D), IBS mixed (IBS-M) and IBS undifferentiated (IBS-U) (Figure 3). Overall, IBS-C was the most frequent category $(43.3 \%$ or 156 of 360), which was most infrequent in the age group of $36-45(26.5 \%)$, followed by the IBS-D category $(35.0 \%$ or 126 of 360 ). The IBS-D category predominated in age groups from 18-45 years, with lower incidence at an age above 46 years. The mixed type IBS-M was diagnosed in 57 patients

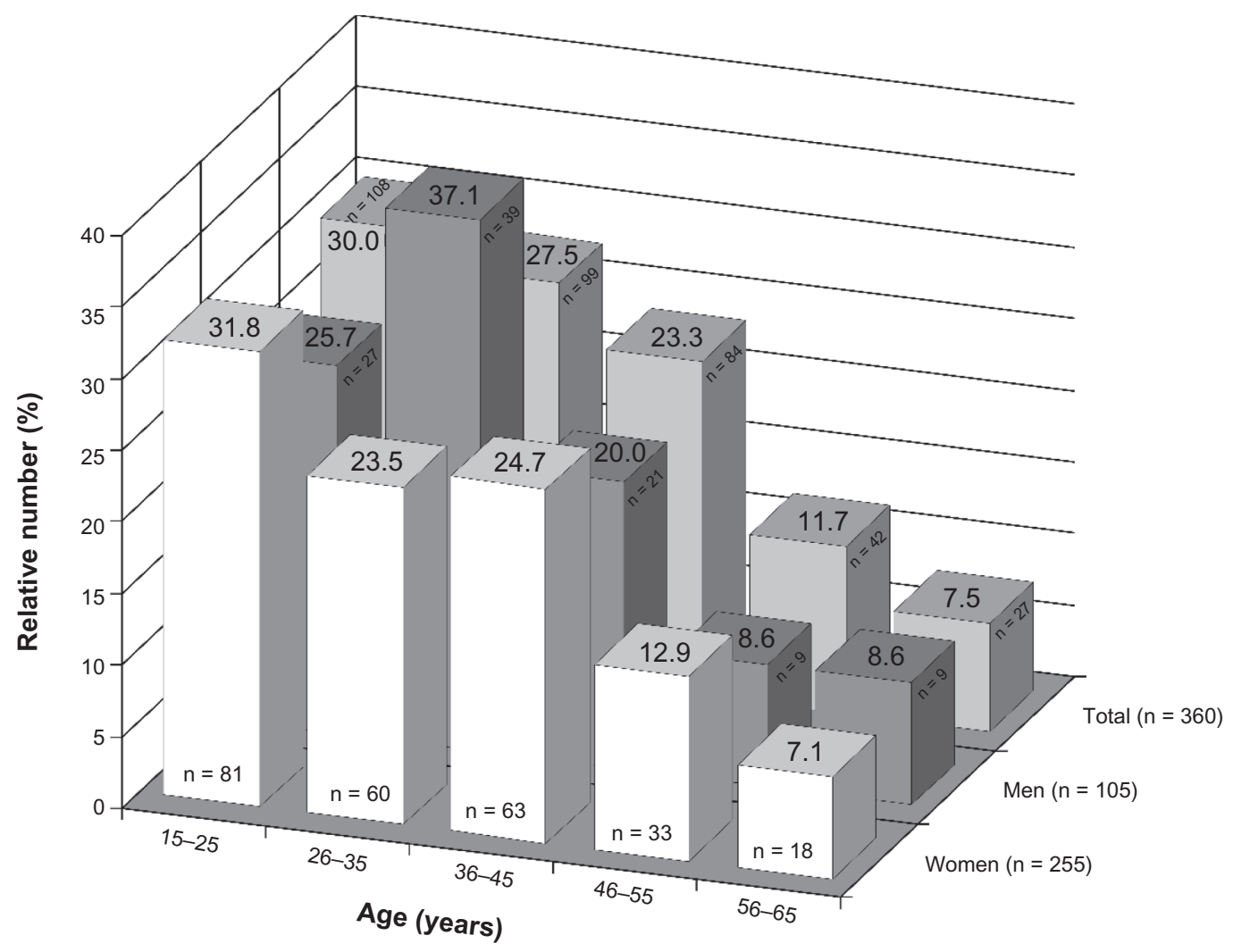

Figure I Gender-dependent age distribution of patients at onset of IBS symptoms. Abbreviation: IBS, Irritable Bowel Syndrome. 


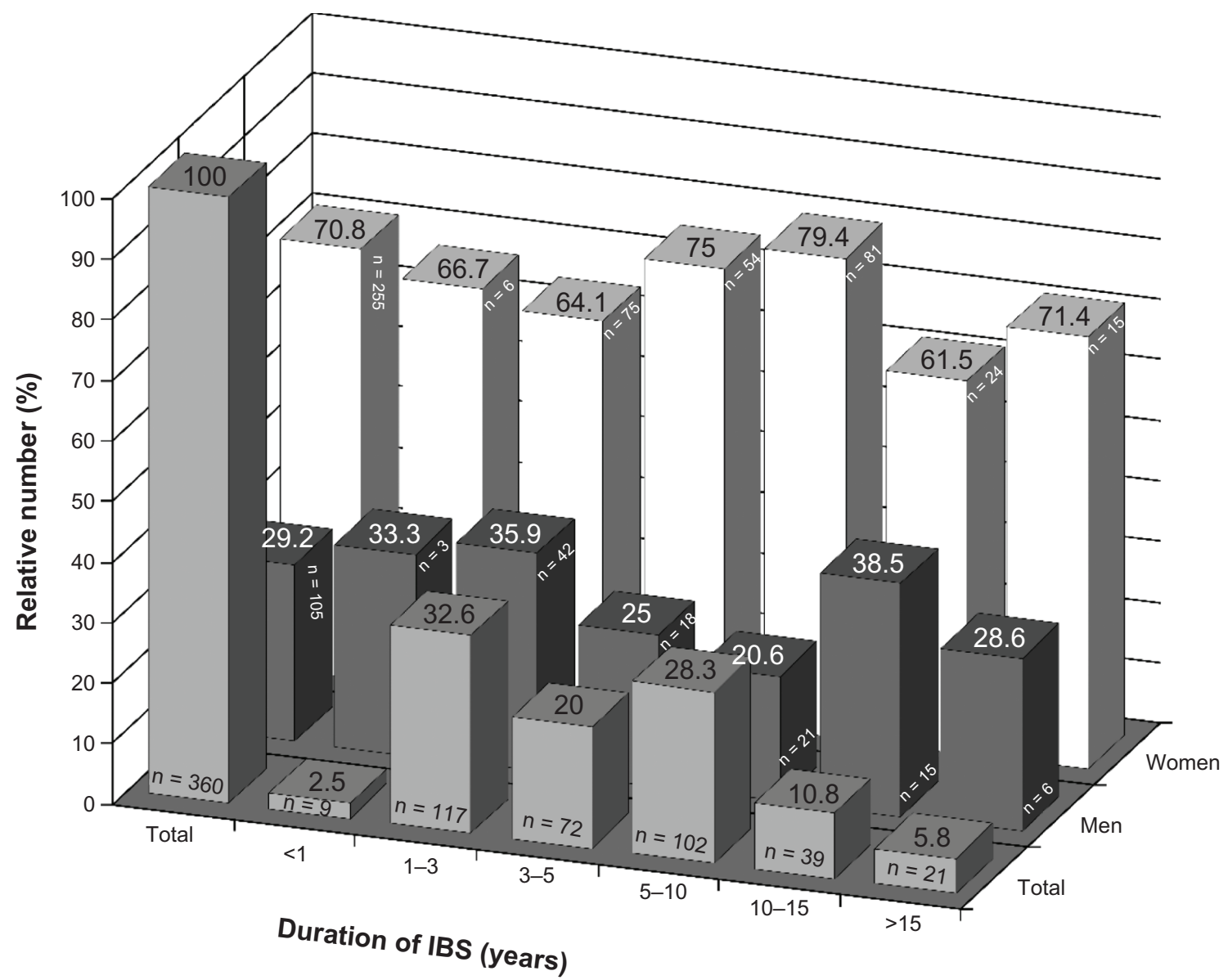

Figure 2 Gender-dependent distribution of duration of IBS symptoms at first diagnosis. Abbreviation: IBS, Irritable Bowel Syndrome.

(15.8\%) and prevailed in the two age groups $18-25$ and 36-45 years. IBS-U was diagnosed in a total of $5.8 \%$ of patients, the percentage increasing with age of patients, ie, it was most frequently diagnosed in the older patients.

We also determined the incidence of predisposing factors for IBS. The factors occurring most frequently were stress (40.8\%) and chronic urogenital disorders (35.6\%) followed by bowel infections (27.5\%), low physical activity (25.8\%) and obesity (20.0\%) (Figure 4).

\section{Efficacy}

Pain intensity

Intensity of pain before treatment and after 28 days' therapy with either mesalazine or conventional therapy without mesalazine was judged by the patients on a visual analog scale (0-10). In all IBS categories, the pain intensity was significantly lower in the mesalazine group $(1.4 \pm 0.4, n=120$ of 360 patients) compared with the control group (3.8 \pm 0.6 , $\mathrm{n}=240$ of 360 patients: see Figure 5). The highest pain score was determined in the IBS-U group $(8.7 \pm 0.9)$, which was significantly higher compared to the other pain scores before treatment, except for the pain score in IBS-M. Mesalazine was less effective in IBS-M and IBS-U, albeit significantly better compared with controls within each particular IBScategory. The difference between the pain score in the mesalazine group with IBS-U is significant, compared with all other groups $(P<0.01)$.

\section{Pain duration}

Pain duration was queried and recorded by the physicians. The most unfavorable situation was found in the IBS-U group, where the mean pain duration was highest (11.0 \pm 1.2 hours per day). This level of pain duration at baseline was significantly higher compared with all other baseline values. Moreover, in this group, there was no difference between the treatment with mesalazine and the control group. In all other IBS categories mesalazine treatment reduced pain duration significantly (Figure 6). The most pronounced reduction in pain duration occurred in the IBS-C and IBS-D group. 


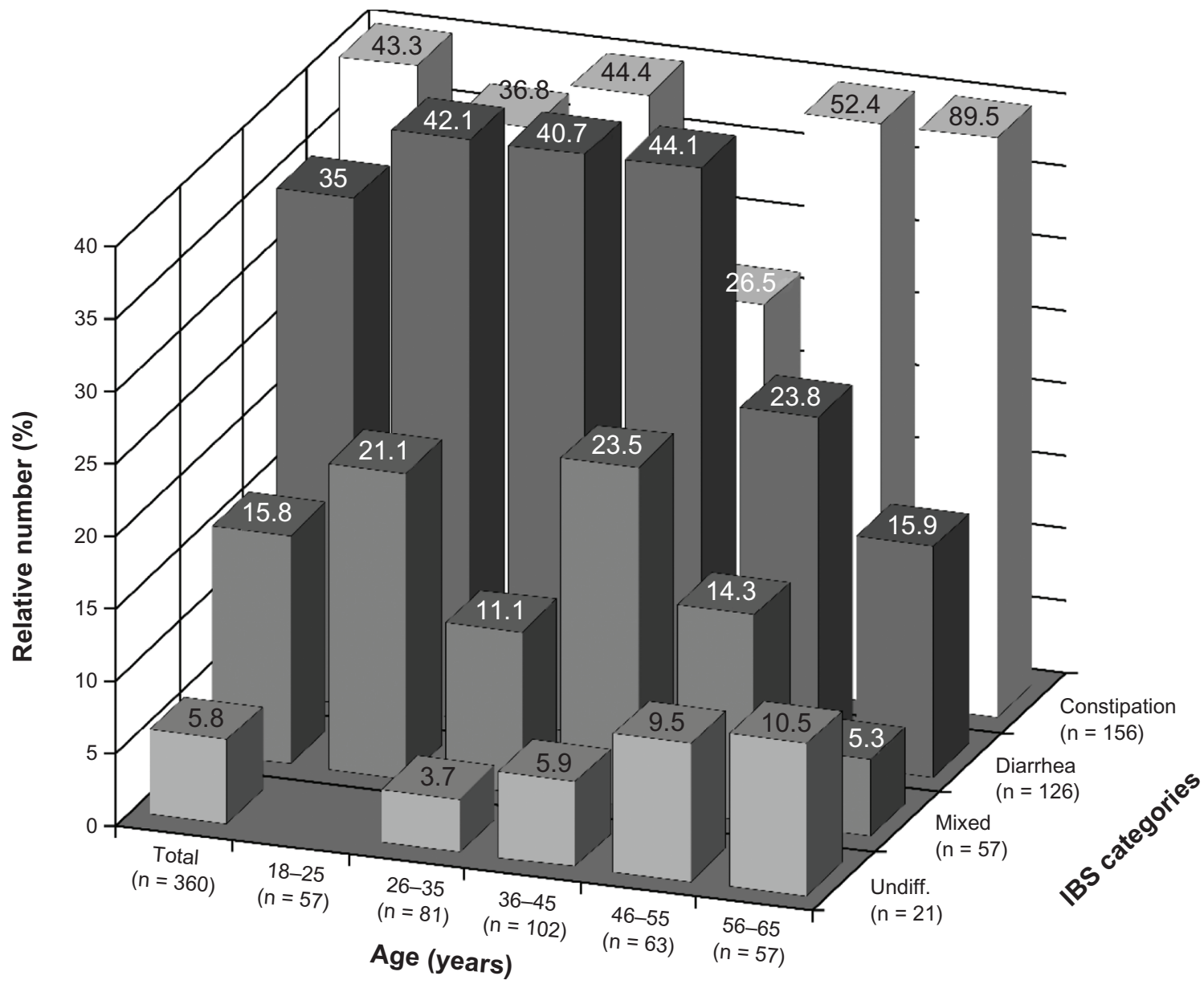

Figure 3 Age distribution of IBS categories.

Abbreviation: IBS, Irritable Bowel Syndrome.

\section{Incidence of stool abnormalities}

At baseline, stool abnormalities were present in all patients. By mesalazine treatment, the number of patients with stool abnormalities was significantly reduced in the IBS-D and IBS-U group only. In each case, the treatment of IBS by standard or mesalazine therapy provided a significant reduction in the percentage of patients with stool abnormalities (Figure 7).

\section{Incidence of meteorism}

At baseline most patients suffered from meteorism. Standard therapy and therapy including mesalazine reduced the number of patients with meteorism significantly in all IBS categories. The difference between standard therapy and mesalazine therapy was significant only in the IBS-D and the IBS-M group (Figure 8).

\section{Cytomorphologic findings}

Results of a cytomorphologic analysis of brush biopsies in patients with different categories of IBS at baseline, which was performed to assess possible differences between IBS categories, are presented in Figure 9. Figure 9 includes only cytomorphologic parameters with significant differences to the basic population. Significant differences were seen between the basic population $(\mathrm{n}=150)$ and the IBS-C group (significantly less "epithelial cells with degeneration", column 3), the IBS-D group (significantly more "pavement cells without changes", column 1, and significantly lower incidence of "mixed bacterial flora", column 5), the IBS-M group (significantly more "columnar epithelial cells", column 2), and the IBS-U group (significantly higher incidence of "nuclear polymorphism in epithelial cells", column 4, and significantly higher incidence of "mixed bacterial flora", column 5).

Incidence of cytomorphologic parameters following treatment with mesalazine compared with the control group considered the parameters "colon mucus changes", "cytological or histological changes", "epithelial cell degeneration", "singular leukocytes or macrophages", "mild cell infiltrations" and "mucus production" (Figure 10, pairs of columns 1-6). 


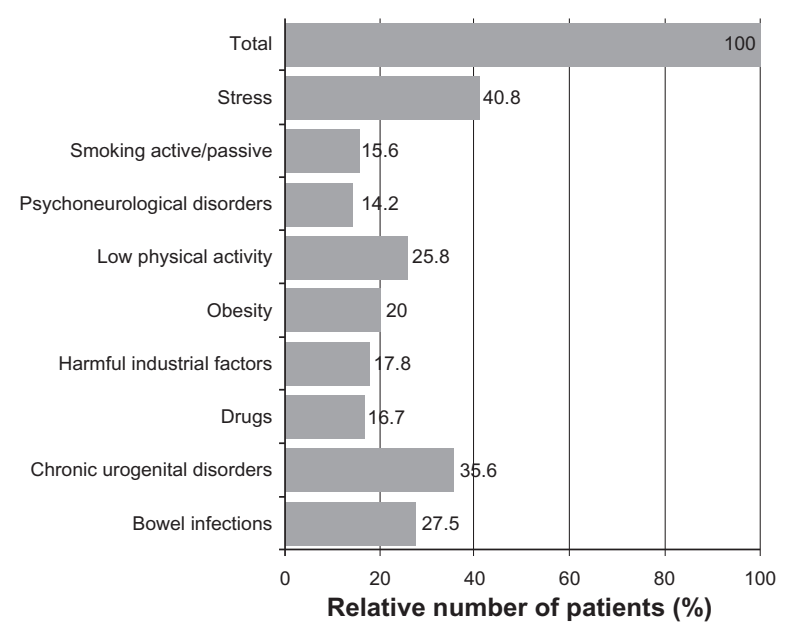

Figure 4 Frequency of predisposing factors ( $100 \%$ equals $n=360$ ).

The parameters "epithelial cell degeneration" (column 3) and "mucus production" (column 6) showed no significant difference between mesalazine treatment and controls. With all other parameters the difference between treatment and controls was significant $(P<0.05$, columns 1 and $4 ; P<0.01$, columns 2 and 5), ie, reduction of colon mucus changes, reduction of cytologic or histologic changes, reduction of singular leukocytes or macrophages and less cell infiltrations as a result of mesalazine treatment.

Cell infiltrations were found in $2(6.7 \%)$ patients, who received mesalazine in contrast to $20(33.3 \%)$ patients in the control group $(P<0.01)$. Abnormal mucus production was seen in $8(26.7 \%)$ patients in the mesalazine group and 27 (45.0\%) patients in the control group (Figure 10).

Most patients with cytomorphologic changes after treatment were between 38 and 47 years old, suffered from IBS for more than 3 years, and had several predisposing factors and endoscopic changes before treatment. 12 of 34 (35.3\%) patients from this group suffered from constipation type IBS.

For morphological evaluation of peculiarities of the colon mucosa, histological analyses were performed in 90 IBS patients who had signs of inflammatory reactions during endoscopic examination. The histologic pattern and changes of the intensity of the colon mucosa showed considerable variations. Abnormal mucus production and moderate inflammatory changes prevailed in the IBS patients examined. A number of 39 (43.3\%) patients had a regular columnar epithelium, single goblet cells and normal numbers of endocrinocytes (Figure 11).

A flattening of the superficial epithelium of $10-15 \mu \mathrm{m}$ was found in $30(33.3 \%)$ patients, and foci of desquamation in $18(20.0 \%)$ IBS patients (Figure 12$)$.
An abundance of crypts with a diameter of $80 \mu \mathrm{m}$ was observed. Goblet cells in crypts predominated in 50 (55.6\%) IBS patients at the mucus production phase, which could be evidence of mucus hyperproduction (Figure 13). In 41 $(45.6 \%)$ patients, the structure of goblet cells appeared normal. The composition of mucus had changed in 52 (57.8\%) IBS patients. In $32(35.6 \%)$ patients, the balance between sulfated and non-sulfated glucosaminoglycans and glycoproteins was altered according to the alcian blue staining (data not shown). The level of sulfated glycoproteins had increased. In 20 (22.2\%) IBS patients a minor decrease in PAS-reaction of mucus in goblet cells was observed (data not shown).

Edemata of the intercryptal space were present in 35 (38.9\%) patients (Figure 14B). At all investigated biopsies mild cell infiltrations could be seen. The infiltrates consisted of plasmocytes $(40 \%-50 \%)$ and lymphocytes $(30 \%-40 \%)$ : evidence of eosinophils and fibroblasts was found in the basal part of the mucosa (37 patients, 41.1\%; Figure 14A, B).

In the submucous layer abnormal vascular patterns were present in 64 (71.1\%) IBS patients. Abundant venous microcapillaries and sometimes venous stasis phenomena were present. Occasionally, foci of lymphoid and plasmocytic infiltrations and lymphoid follicles were detected in the submucosal layer (Figure 15A, B).

\section{Safety analysis}

The frequency of adverse events (AEs), clinically relevant changes in laboratory analysis and vital signs were assessed. A total of 44 AEs were reported in 42 (11.7\%) patients. Among them 13 patients (10.8\%) obtained mesalazine and standard treatment and 29 patients $(12.1 \%)$ received standard treatment only. No drug-related AEs were revealed in either group. The AEs most frequently reported in both groups of patients were headache, nasopharyngitis, and flu-like infection. There was no significant difference in frequency of these AEs in the two groups. All patients who reported AEs, experienced AEs of mild intensity. There was no evidence for serious AEs in IBS patients during the study.

\section{Discussion}

The pathophysiology of IBS has long been discussed and is still to be elucidated. The Rome Foundation has spent many years collecting data from experts and updating our knowledge about this disease, ${ }^{2,23}$ a process that continuously results in improvement in diagnosis and characterization of different aspects of IBS and thus the optimization of individual patient-oriented therapies. 


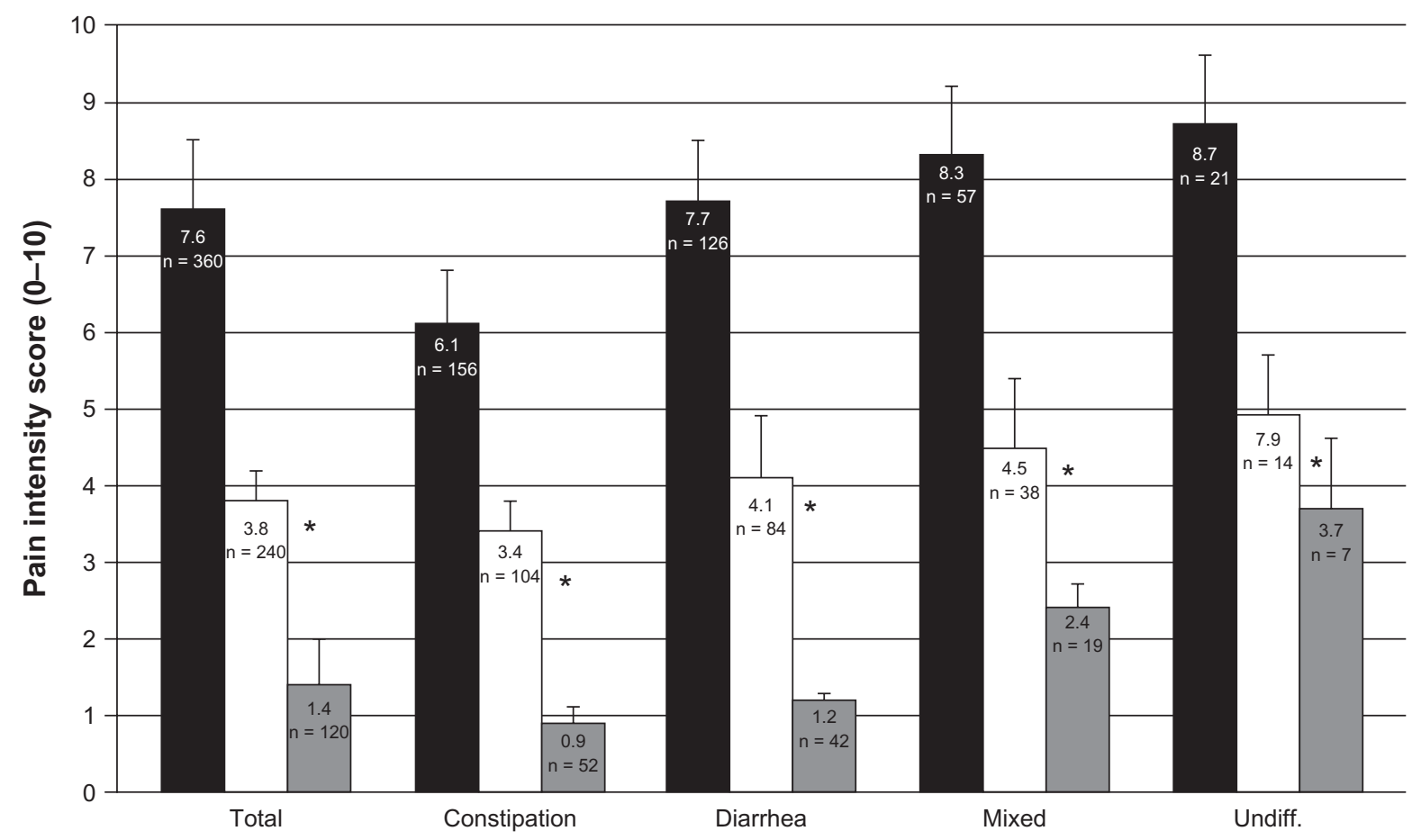

Figure 5 Pain intensity judged by patients with different categories of IBS (constipation, diarrhea, mixed and undifferentiated type) on a visual analog scale (0-I0).

Notes: "Total" refers to the intention to treat population; columns with significant difference between control and mesalazine group are marked by $*(P<0.05)$. Values before treatment are represented by black columns, control group values are in white columns and values from the mesalazine group are in gray. Vertical bars represent standard deviations.

Abbreviation: IBS, Irritable Bowel Syndrome.

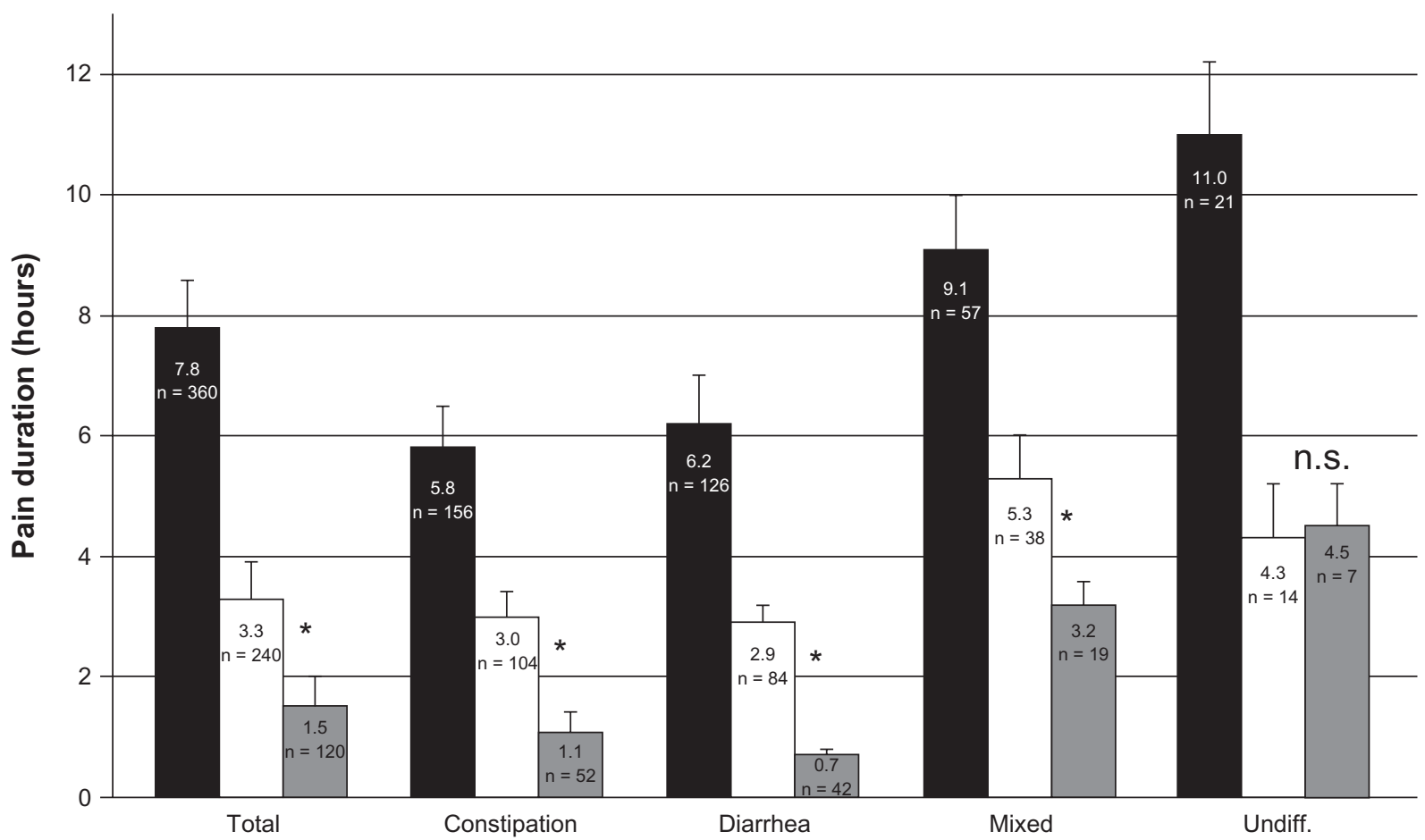

Figure 6 Pain duration (hours per day) in patients with different categories of IBS (constipation, diarrhea, mixed and undifferentiated type).

Notes: "Total" refers to the intention to treat population; columns with significant difference between control and mesalazine group are marked by *(P < 0.05$)$; "n.s.." not significant. Values before treatment are represented by black columns, control group values are in white columns, and values from the mesalazine group are in gray. Vertical bars represent standard deviations.

Abbreviation: IBS, Irritable Bowel Syndrome. 


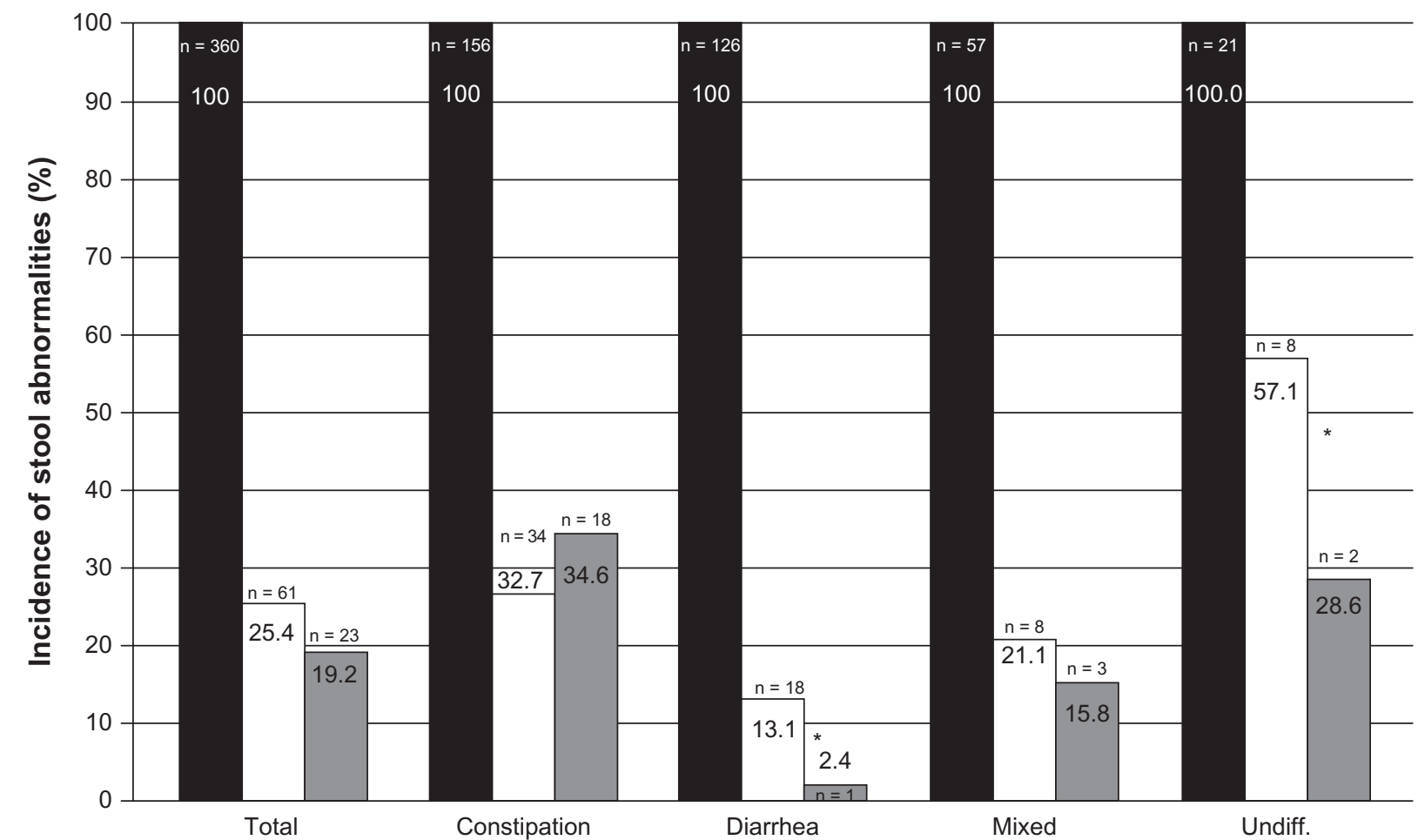

Figure 7 Incidence of stool abnormalities (\%) in patients with different categories of IBS (constipation, diarrhea, mixed and undifferentiated type).

Notes: "Total" refers to the intention to treat population; columns with significant difference between control and mesalazine group are marked by $*(P<0.05)$. Values before treatment are represented by black columns, control group values are in white columns, and values from the mesalazine group are in gray. Abbreviation: IBS, Irritable Bowel Syndrome.

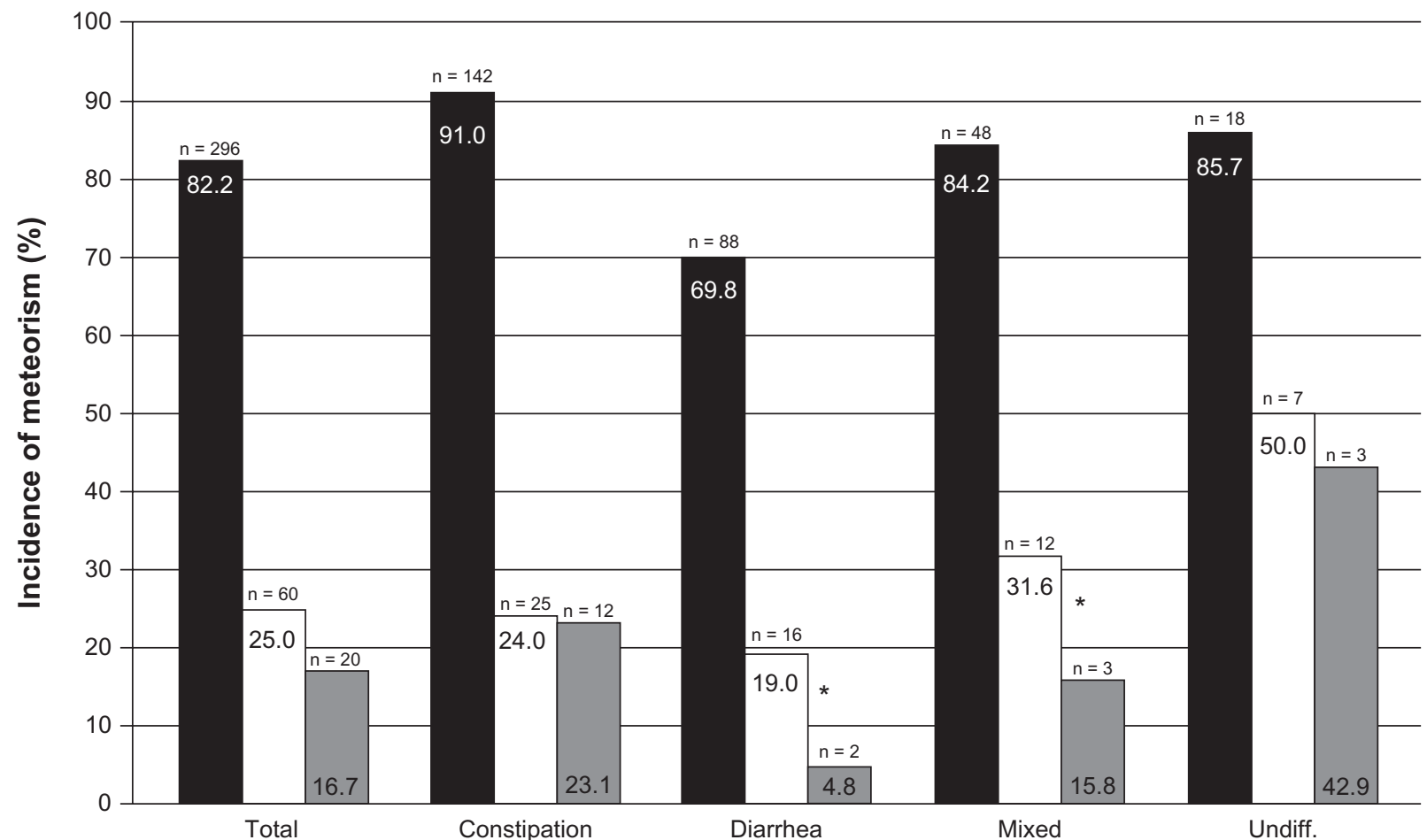

Figure 8 Incidence of meteorism (\%) in patients with different categories of IBS (constipation, diarrhea, mixed and undifferentiated type).

Notes: "Total" refers to the intention to treat population; columns with significant difference between control and mesalazine group are marked by $*(P<0.05)$. Values before treatment are represented by black columns, control group values are in white columns, and values from the mesalazine group are in gray.

Abbreviation: IBS, Irritable Bowel Syndrome. 


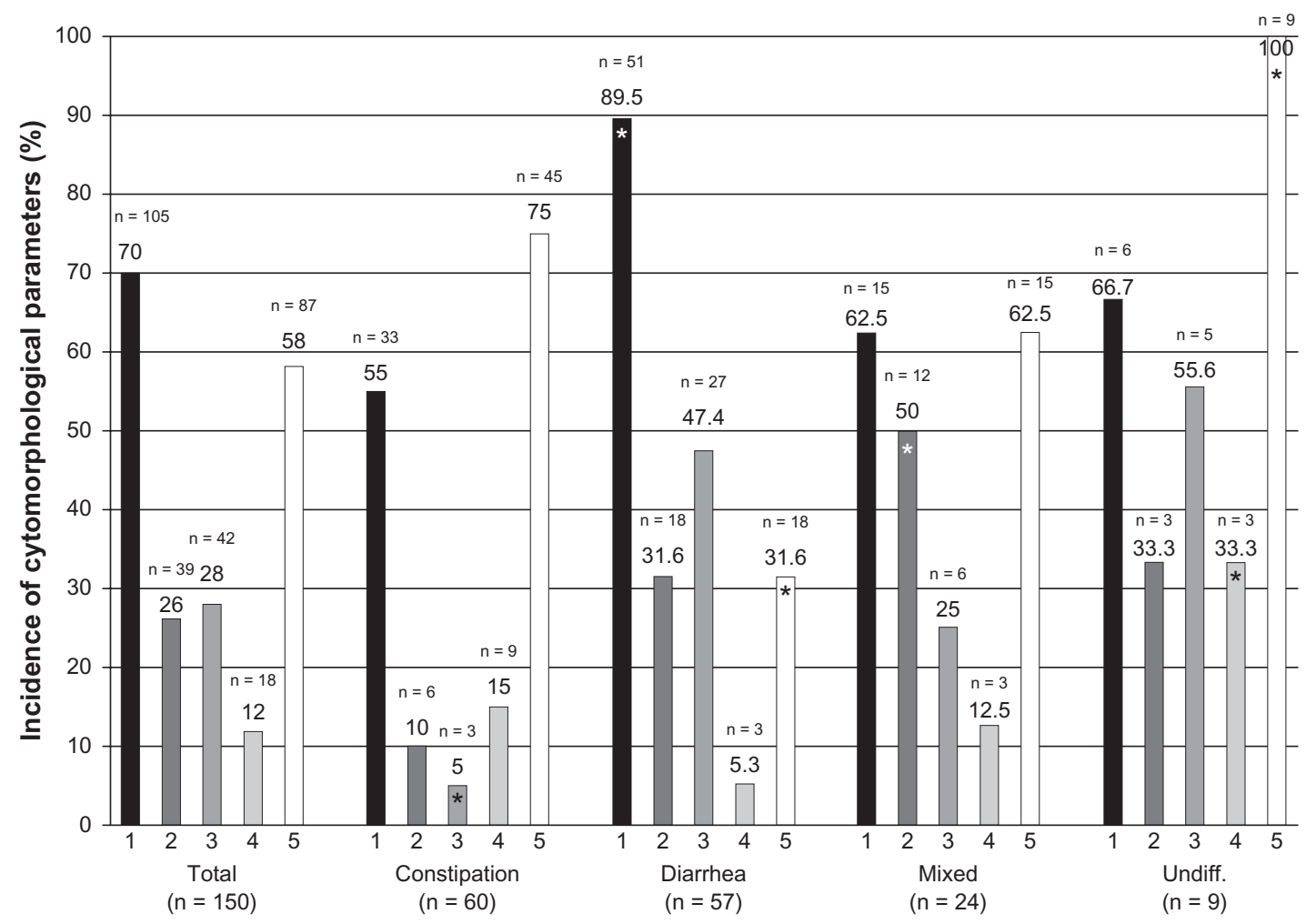

Figure 9 Incidence (\%) of cytomorphologic parameters in patients with different categories of IBS (constipation, diarrhea, mixed and undifferentiated type).

Notes: Only those parameters are represented where significant differences occurred between the total group and the individual categories. I - Pavement epithelial cells without changes, 2 - Columnar epithelial cells, 3 - Epithelial cells with degeneration, 4 - Nuclear polymorphism in epithelial cells, 5 - Mixed bacterial flora; columns with significant difference are marked by $*(P<0.05)$.

Abbreviation: IBS, Irritable Bowel Syndrome.

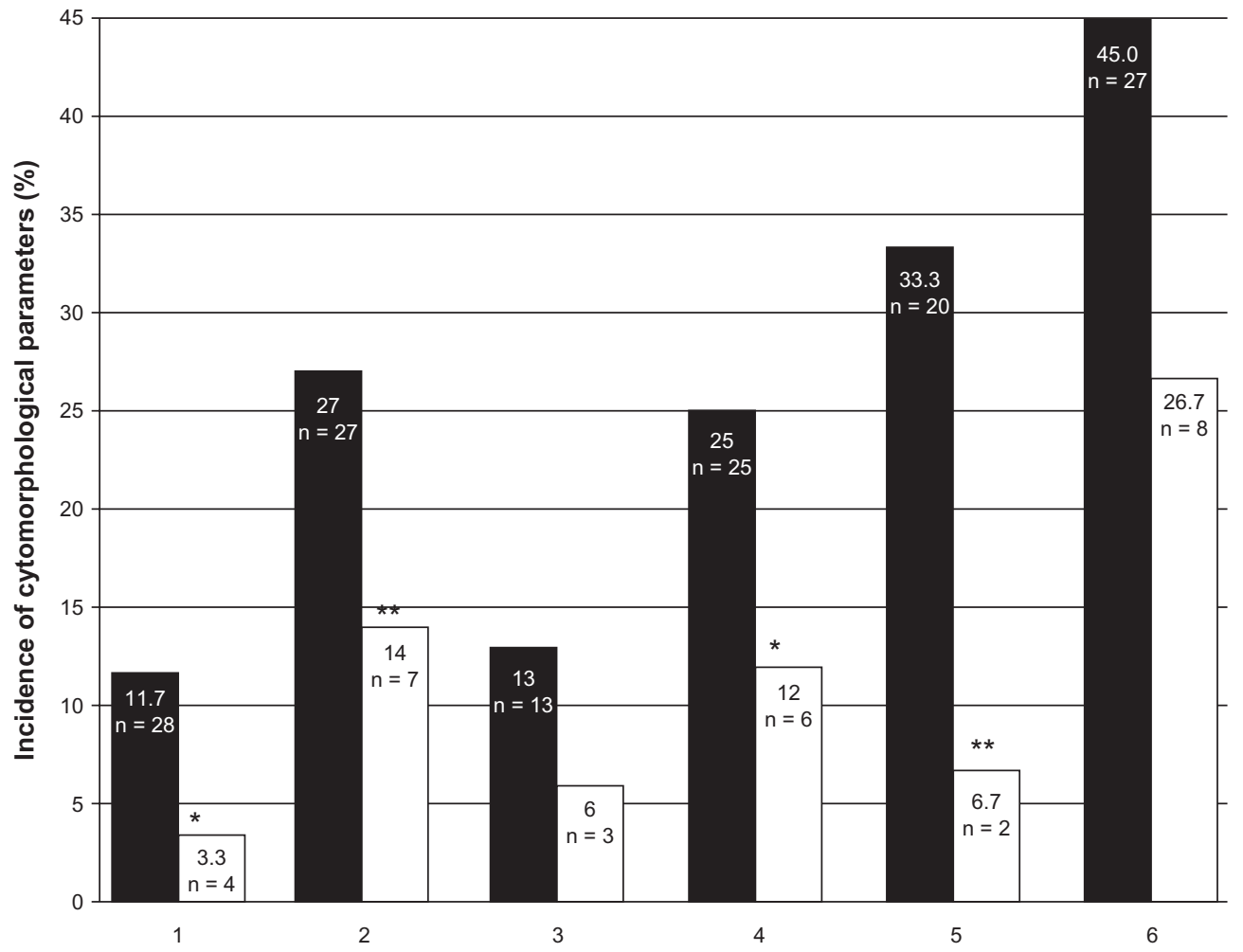

Figure 10 Incidence of cytomorphologic parameters after 28 day of treatment with mesalazine (white columns) compared with controls (black columns).

Notes: I - Colon mucus changes, 2 - Cytological or histological changes, 3 - Epithelial cell degeneration, 4 - Singular leukocytes or macrophages, 5 - Mild cell infiltrations, 6 - Mucus production; columns with significant difference are marked by $*(P<0.05)$ and $* *(P<0.0 \mathrm{I})$ respectively. 


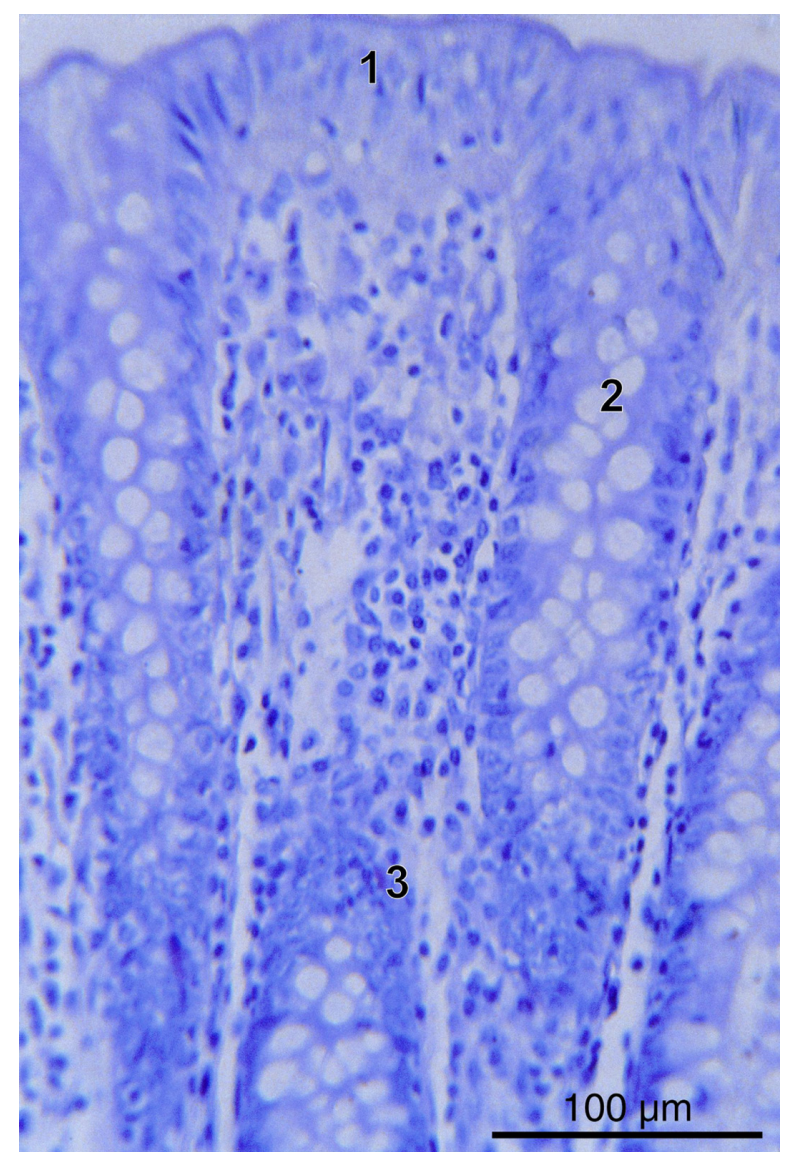

Figure I I Colon mucosa of IBS patient (I - columnar epithelium, 2 - goblet cells, 3 - endocrinocytes, hematoxylin-eosin staining, bar $=100 \mu \mathrm{m})$.

Abbreviation: IBS, Irritable Bowel Syndrome.

The pharmacological treatment of IBS is still controversial, due to the lack of knowledge about causal interdependencies. A plethora of drugs has been suggested for treatment of diarrhea, constipation and abdominal pain in IBS, but most treatments help only in a selected cohort of patients, and a significant and convincing success is still missing., ${ }^{2,12}$ That is

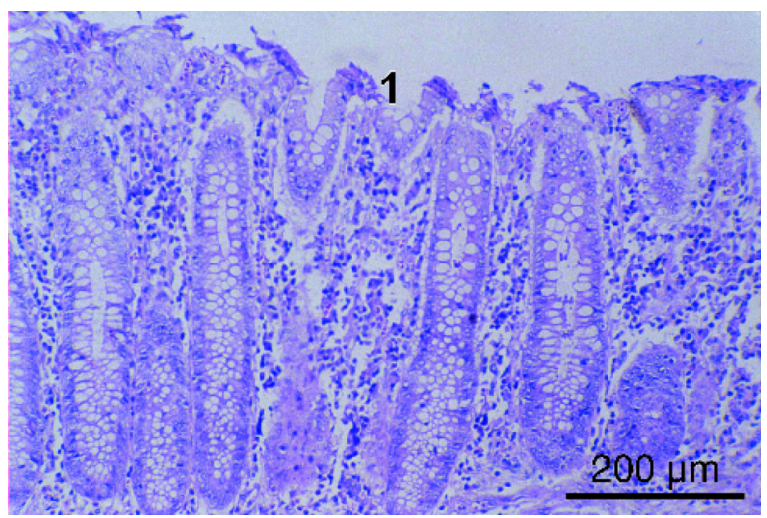

Figure 12 Flattening of superficial epithelium (I) in colon mucosa in IBS patient (hematoxylin-eosin staining, bar $=200 \mu \mathrm{m}$ ).

Abbreviation: IBS, Irritable Bowel Syndrome.

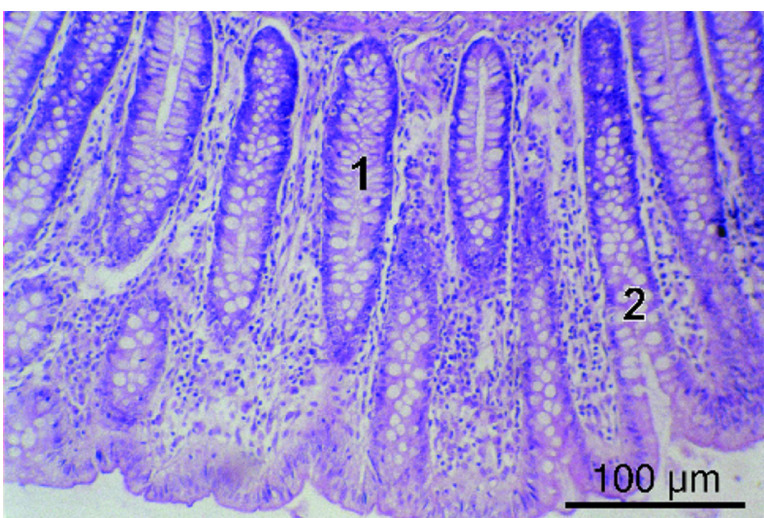

Figure 13 Goblet cells (I), crypts (2) in colon mucosa in IBS patient (hematoxylineosin staining, bar $=100 \mu \mathrm{m})$.

Abbreviation: IBS, Irritable Bowel Syndrome.

why Barbara et al recently concentrated on the importance of immune activation in the context of IBS. ${ }^{12}$ Several studies seem to corroborate the hypothesis that immune activation may contribute to symptom generation in IBS patients. ${ }^{24-32}$ Consequently the Barbara group initiated a "proof of concept" study to investigate the efficacy of mesalazine, a candidate well known and established as a remedy for inflammatory bowel diseases like ulcerative colitis and Crohn's disease. ${ }^{33}$ They found that mesalazine markedly reduced
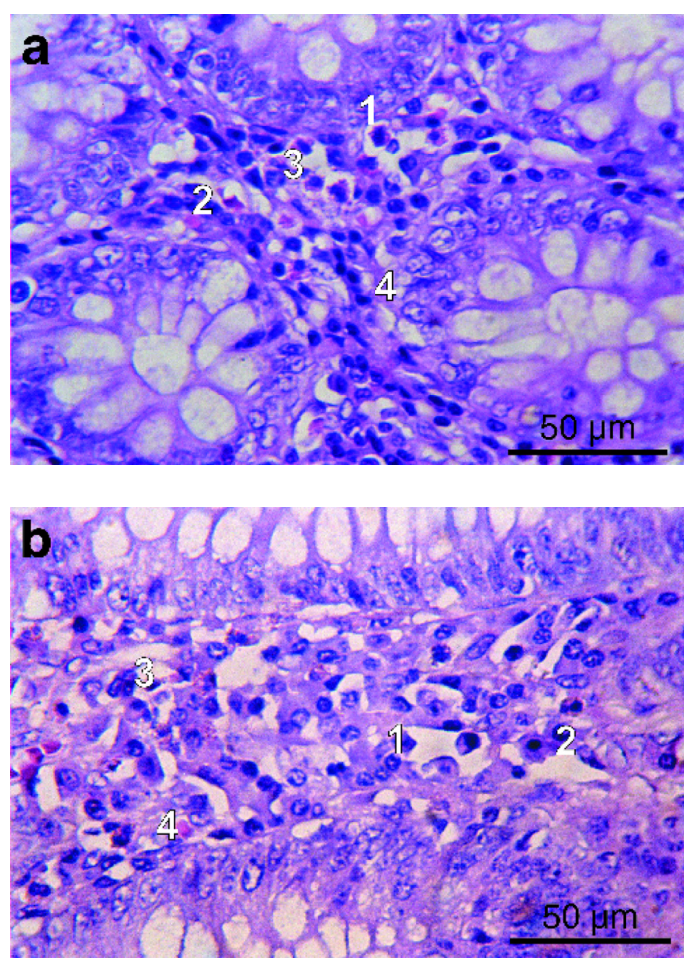

Figure 14 Cell infiltrations A) and edema B) in colon mucosa in IBS patient (I - plasmocytes, 2 - lymphocytes, 3 - eosinophils, 4 - fibroblasts, hematoxylineosin staining). Bars $=50 \mu \mathrm{m}$.

Abbreviation: IBS, Irritable Bowel Syndrome. 

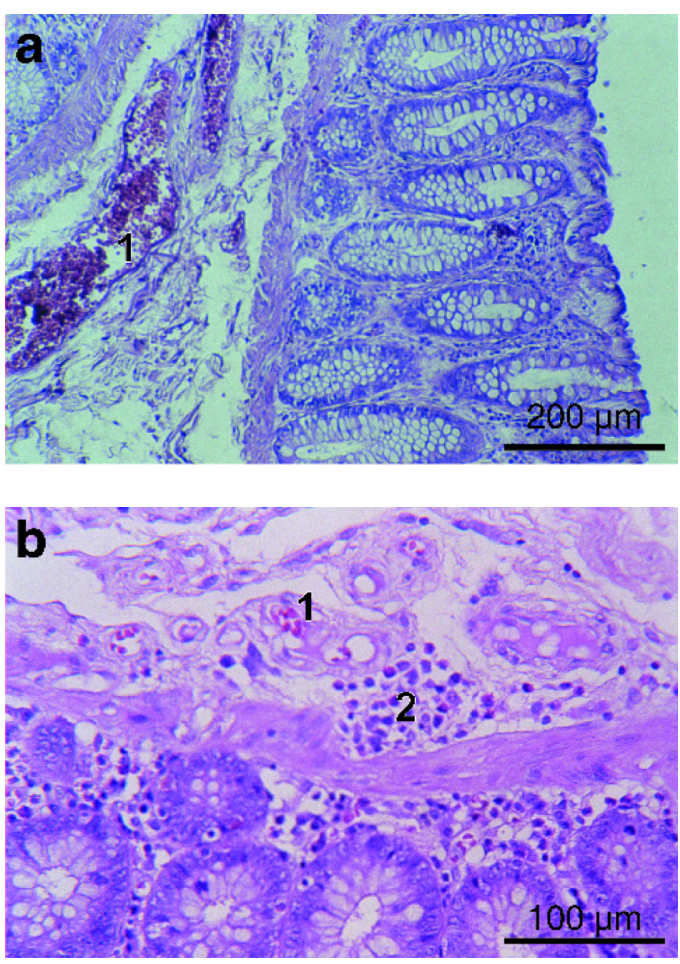

Figure 15 Plethora of microcapillaries A) and areas of cell infiltrations in the submucous layer of the submucosa B) of IBS patient (I - microcapillaries with venous stasis phenomena, 2 - plasmocytic infiltrations, hematoxylin-eosin staining). Bars: $\mathrm{a}=200 \mu \mathrm{m}, \mathrm{b}=100 \mu \mathrm{m}$.

Abbreviation: IBS, Irritable Bowel Syndrome.

mucosal immune cells, especially mast cells, and significantly improved general well-being. ${ }^{34}$ In contrast to our own findings that abdominal pain was reduced significantly in all categories of IBS, this study did not demonstrate a significant effect on pain and bowel habit. Moreover, in our study, the incidence of meteorism and stool abnormalities was reduced significantly at least in some of the IBS subtypes. Concerning indications of inflammatory and immune-related events, however, we could not find significant traces of abnormalities which could account for immune activation as a basis for IBS symptoms.

5-ASA was selected as a treatment for IBS because of the evidence of morphological signs of inflammation. Probably the presence of latent inflammatory processes in colon mucosa can explain the long-term recurrence of IBS with resistance to standard IBS treatments. 5-ASA is an anti-inflammatory drug. The mechanism of action aims at the inhibition of metabolism of arachidonic acid (predominantly the lipoxygenase pathway). In contrast, rifaximine is an antibiotic, effective in cases of manifest colon infections like post infectious IBS and bacterial overgrowth syndrome that may occur as an exacerbation of IBS.
At the same time, mucosal micro-inflammation in IBS can be a result of impact on visceral innervation, and an imbalance of serine/histamine. Amine precursor uptake decarboxylase (APUD) peptides are not related to infections. Hence, in our opinion, mesalazine is better suited for basic treatment of IBS considering the main pathogenetic mechanisms.

\section{Conclusion}

Mesalazine is effective in reducing abdominal pain in patients with different types of IBS. The duration of pain is also reduced significantly by treatment with mesalazine. Moreover, meteorism and abnormal stool pattern are improved significantly in some subtypes of IBS.

\section{Acknowledgments}

For preparation of the manuscript, editorial assistance was provided by the editorial office of medicaltext.de, Königswinter, Germany, on behalf of Dr Falk Pharma GmbH, Freiburg, Gemany.

\section{Disclosure}

The study was carried out on the sole responsibility of AED as a professor of the National Medical University of Donetsk and the Gastroenterological Center of Poltava Hospital Clinic, Poltava, Ukraine, and at the exclusive expense of the three participating hospitals. There was no conflict of interest between the authors and the respective institutions. The authors declare that no financial or other conflict of interest exists in relation to the content of the article.

\section{References}

1. Powell R. On certain painful afflictions of the intestinal canal. Med Trans Royal Coll Phys. 1818;6:106-107.

2. Longstreth GF, Thompson WG, Chey WD, Houghton LA, Mearin F, Spiller RC. Functional bowel disorders. Gastroenterology. 2006;130:1480-1491.

3. Loginov AS, Parfenov AI. Intestinal diseases. Moscow: Meditsina Publishers; 2000;137-211.

4. World Global Practice Guideline Irritable Bowel Syndrome. WGO April, 2009, available at: http://www.worldgastroenterology.org/assets/down loads/en/pdf/guidelines/20_irritable_bowel_syndrome.pdf. (03/15/2009).

5. Lembo AJ, Drossman DA. Contemporary diagnosis and management of irritable bowel syndrome. Newton (PA): Handbooks in Healthcare Company; 2002;148.

6. Drossman DA, Creed FH, Olden KW, Svedlund J, Toner BB, Whitehead WE. Psychosocial aspects of the functional gastrointestinal disorders. Gut. 1999;Suppl 2:1125-1130.

7. Clouse RE, Alpers DH, Hockenbery DM, DeSchryver-Kecskemeti K. Pericrypt eosinophilic enterocolitis and chronic diarrhea. Gastroenterology. 1992;103:168-176.

8. Drossman DA, Camilleri M, Mayer EA, Whitehead WE. AGA Technical review on irritable bowel syndrome. Gastroenterology. 2002;123: 2108-2131. 
9. Mayer EA, Gebhardt GF. Basic and clinical aspects of visceral hyperalgesia. Gastroenterology. 1994;107:271-293.

10. Mertz H, Morgan V, Tanner G, et al. Regional cerebral activation in irritable bowel syndrome and control subjects with painful and nonpainful rectal distention. Gastroenterology. 2000;118:842-848.

11. Drossman DA, Ringel Y, Vogt BA, et al. Alterations of brain activity associated with resolution of emotional distress and pain in a case of severe irritable bowel syndrome. Gastroenterology. 2003;124: 754-761.

12. Barbara G, Stanghellini V, Cremon C, et al. Aminosalicylates and other anti-inflammatory compounds for irritable bowel syndrome. Dig Dis. 2009;27(Suppl 1):115-121.

13. Barbara G, De Giorgio R, Stanghellini V, Cremon C, Salvioli B, Corinaldesi R. New pathophysiological mechanisms in irritable bowel syndrome. Aliment Pharmacol Ther. 2004;20(Suppl 2):1-9.

14. Klooker TK, Braak B, Koopman KE, et al. The mast cell stabiliser ketotifen decreases visceral hypersensitivity and improves intestinal symptoms in patients with irritable bowel syndrome. Gut. 2010;59: 1213-1221.

15. Macsharry J, O'Mahony L, Fanning A, et al. Mucosal cytokine imbalance in irritable bowel syndrome. Scand J Gastroenterology. 2008;43:1467-1476

16. Manning AP, Thompson WG, Heaton KW, Morris AF. Towards positive diagnosis of the irritable bowel. Br Med J. 1978;2:653-654.

17. Kruis W, Thieme C, Weinzhierl M, Schussler P, Holl J, Paulus W. A diagnostic score for the irritable bowel syndrome. Its value in the exclusion of organic disease. Gastroenterology. 1984;87:1-7.

18. Thompson WG, Dotevall G, Drossman DA, Heaton KW, Kruis W. Irritable bowel syndrome: Guidelines for the diagnosis. Gastroenterol Int. 1989;2:92-95.

19. Drossman DA, Thompson WG, Talley NJ, Funch-Jensen P, Janssens J, Whitehead WE. Identification of subgroups of functional bowel disorders. Gastroenterol Int. 1990;3:159-172.

20. Drossman DA, Corazziari E, Talley NJ, Thompson WG, Whitehead WE. Diagnostic criteria for functional gastrointestinal disorders. In: Drossman DA, Corazziari E, Talley NJ, Thompson WG, Whitehead WE, editors. Rome II. The functional gastrointestinal disorders. Diagnosis, Pathophysiology and Treatment: A Multinational Consensus. McLean (VA): Degnon and Associates; 2000.

21. Palsson OS, Taub E, Cook E III, Burnett CK, McCommons JJ, Whitehead WE. Validation of Rome Criteria for functional gastrointestinal disorders by factor analysis. Am J Gastroenterol. 2000;91:1996.
22. Vanner SJ, Depew WT, Paterson WG, et al. Predictive value of the Rome criteria for diagnosing the irritable bowel syndrome. Am J Gastroenterology. 1999;94:2912-2917.

23. Spiegel B, Camilleri M, Bolus R, et al. Psychometric evaluation of patient-reported outcomes in irritable bowel syndrome randomized controlled trials: A Rome Foundation Report. Gastroenterology. 2009; 137:1944-1953

24. Barbara G, Stanghellini V, Cremon C, De Giorgio R, Corinaldesi R. What is the effect of inflammation on intestinal function? Inflamm Bowel Dis. 2008;14:S140-S144.

25. Isgar B, Harman M, Kaye MD, Whorwell PJ. Symptoms of irritable bowel syndrome in ulcerative colitis in remission. Gut. 1983;24:190-192.

26. Limsui D, Pardi DS, Camilleri M, et al. Symptomatic overlap between irritable bowel syndrome and microscopic colitis. Inflamm Bowel Dis. 2007;13:175-181.

27. Simrén M, Axelsson J, Gillberg R, Abrahamsson H, Svedlund J, Björnsson ES. Quality of life in inflammatory bowel disease in remission: the impact of IBS-like symptoms and associated psychological factors. Am J Gastroenterol. 2002;97:389-396.

28. Spiller R, Garsed K. Postinfectious irritable bowel syndrome. Gastroenterol. 2009;136:1979-1988.

29. Barbara G, Stanghellini V, De Giorgio R, et al. Activated mast cells in proximity to colonic nerves correlate with abdominal pain in irritable bowel syndrome. Gastroenterology. 2004;126:693-702.

30. Cenac N, Andrews CN, Holzhausen M, et al. Role for protease activity in visceral pain in irritable bowel syndrome. J Clin Invest. 2007; 117:636-647.

31. Aerssens J, Camilleri M, Talloen W, et al. Alterations in mucosal immunity identified in the colon of patients with irritable bowel syndrome. Clin Gastroenterol Hepatol. 2008;6:194-205.

32. O'Mahony L, McCarthy J, Kelly P, et al. Lactobacillus and bifidobacterium in irritable bowel syndrome: symptom responses and relationship to cytokine profiles. Gastroenterology. 2005;128: $541-551$.

33. Travis SP, Stange EF, Lémann M, et al. European Crohn's and Colitis Organisation. European evidence based consensus on the diagnosis and management of Crohn's disease: current management. Gut. 2006;55(Suppl 1):i16-i35.

34. Corinaldesi R, Stanghellini V, Cremon C, et al. Effect of mesalazine on mucosal immune biomarkers in irritable bowel syndrome: a randomized controlled proof-of-concept study. Aliment Pharmacol Ther. 2009;30: $245-252$.
Clinical and Experimental Gastroenterology

\section{Publish your work in this journal}

Clinical and Experimental Gastroenterology is an international, peerreviewed, open access journal, publishing all aspects of gastroenterology in the clinic and laboratory, including: Pathology, pathophysiology of gastrointestinal disease; Investigation and treatment of gastointestinal disease; Pharmacology of drugs used in the alimentary tract;

\section{Dovepress}

Immunology/genetics/genomics related to gastrointestinal disease. This journal is indexed on CAS. The manuscript management system is completely online and includes a very quick and fair peer-review system. Visit http://www.dovepress.com/testimonials.php to read real quotes from published authors. 